\title{
PROTAGONISMOS EM TORNO DA OBRA DIÁRIO DE BORDO DO ALMIRANTE NEGRO, DE ELISABETE NASCIMENTO
}

\section{PROTAGONISMS AROUND THE WORK DIÁRIO DE BORDO DO ALMIRANTE NEGRO, BY ELISABETE NASCIMENTO}

Fernanda Oliveira da Silva ${ }^{1}$

\begin{abstract}
Resumo: O presente artigo tem como objetivo apontar a relevância do papel da literatura afro-brasileira para o público infantojuvenil e os protagonismos que a obra Diário de bordo do Almirante Negro, de Elisabete Nascimento, pode promover. A partir dos possíveis diálogos com as contribuições teóricas de Spivak, Djamila Ribeiro e María Lugones, apresentamos as distintas formas de resistência encontradas na obra, considerando a perspectiva de ressignificação dos estereótipos negativos sobre o corpo negro.
\end{abstract}

\begin{abstract}
This article aims to point out the relevance of the role of Afro-brazilian literature for children and adolescents and the protagonism that Elisabete Nascimento's work, Diário de bordo do Almirante Negro, can promote. From the possible dialogues with the theoretical contributions of Spivak, Djamila Ribeiro and María Lugones, we present the different forms of resistance found in the work, considering the perspective of reframing negative stereotypes about the black body.
\end{abstract}

Palavras-chave: Literatura afro-brasileira infantojuvenil. Protagonismo negro. Protagonismo negro feminino. Resistência.

Keywords: Afro-brazilian children and adolescents literature. Black protagonism. Black female protagonism. Resistance.

\section{Introdução}

As obras literárias para crianças e jovens merecem atenção e análise dos conteúdos que as compõem, pois a literatura exerce uma significativa função não apenas na construção críticoleitora da criança, mas também como elemento influenciador na formação da identidade. A partir deste pensamento, interessa-nos, para este breve estudo, evidenciar a importância da literatura afrobrasileira infantojuvenil para seus leitores e os possíveis protagonismos que surgem a partir dessas escritas.

Ao fazer a leitura de algumas narrativas afro-brasileiras voltadas para o público infantojuvenil, pode-se notar que as mesmas corroboram para a afirmação positiva e não estereotipada da cultura e das religiões brasileiras de matrizes africanas. Este aspecto é de extrema importância, pois

1 Mestranda em Literaturas Africanas pela UFRJ e pesquisadora bolsista peloprograma Bolsa Nota 10 da FAPERJ. 
É no contexto da cultura que nós aprendemos a enxergar as raças. Isso significa que, aprendemos a ver negros e brancos como diferentes na forma como somos educados e socializados a ponto dessas ditas diferenças serem introjetadas em nossa forma de ser e ver o outro, na nossa subjetividade, nas relações sociais mais amplas. (MUNANGA, 2006, p. 176)

Diante disso, percebe-se a necessidade de uma reeducação social, que pode surgir por meio das narrativas afro-brasileiras. Assim, consideramos que a literatura é também "imagem e transfiguração" (CANDIDO, 2004, p. 175) da realidade e, ao imitar e (re) criar, exerce influência no comportamento do leitor, sobretudo no caso de crianças por não perceberem limites entre a ficção e o real. Logo, compreende-se que a literatura é essencial para a formação, à medida que "confirma e nega, propõe e denuncia, apóia e combate, fornecendo a possibilidade de vivermos dialeticamente os problemas" (CANDIDO, 2004, p. 175).

Além do mais, importante é ressaltar que "a construção da identidade do indivíduo iniciase na sua infância e vai sofrer influência de todos os referenciais com os quais ele irá se deparar ao longo de sua história. Sejam positivos ou negativos" (MARIOSA; REIS, 2011, p. 46). Neste sentido, a formação da identidade da criança está ligada aos referenciais a ela apresentados, sejam eles brinquedos, filmes, desenhos ou histórias infantis. Histórias essas nas quais apresentam-se fadas, heróis, princesas, príncipes e outras personagens, na maioria da vezes, brancos e de origem europeia. Consequentemente, isto faz com que as crianças acreditem que o padrão de beleza e de bondade estejam conectados a essas imagens. Logo, desde cedo, o sentimento de inferioridade, de apagamento e de aparência inadequada é relacionado à criança negra, que cresce acreditando que, para ser aceita ou reconhecida, precisa embranquecer-se.

Desse modo, a literatura afro-brasileira infantojuvenil torna-se essencial, pois apresenta-se como um meio que inspira o protagonismo negro. Por isso, incentivar a leitura de obras com esse perfil, "onde os heróis são referências em histórias como protagonistas negros, pode contribuir, tanto para a construção da identidade e da autoestima de crianças negras como para a valorização da convivência na diversidade com a criança branca" (MARIOSA; REIS, 2011, p. 43).

Com o intuito de demonstrar os possíveis protagonismos negros, selecionamos como corpus a obra Diário de bordo do Almirante Negro, de Elisabete Nascimento. A escritora traz, em seu livro, a ficcionalização da história de João Cândido, líder da Revolta da Chibata² ${ }^{2}$ Publicado em 2011, com ilustrações que parecem ter sido idealizadas cuidadosamente, a obra exerce uma função didática e também faz com que o leitor se inquiete diante da narrativa apresentada. Por isso, ousamos afirmar que uma das propostas de Nascimento é trazer à tona as vozes negras silenciadas e, assim, denunciar as diversas opressões que sempre ocorreram contra o corpo negro e contar como houve protagonismo

2 Movimento de insubordinação organizado pelos soldados da Marinha brasileira em 1910. A revolta ocorreu nas embarcações da Marinha que estavam atracadas na Baía de Guanabara e foi impulsionada, sobretudo, pela indignação dos marinheiros com os castigos físicos que recebiam como forma de punição. 
através de muita resistência. Para isso, o presente artigo divide-se, além desta introdução, em primeiro lugar, no protagonismo da autora, que é possível a partir da escrita da obra. No segundo momento, o protagonismo do personagem principal e das personagens femininas e, por último, as considerações finais, onde retomaremos algumas questões desenvolvidas ao longo deste estudo.

\section{Protagonismo da Autora}

Ao observarmos que o protagonismo negro é uma das temáticas de Diário de bordo do Almirante Negro, compreendemos a necessidade de apresentar Elisabete Nascimento e analisar como a obra possibilita o protagonismo não apenas das personagens, mas também o da autora.

A escritora nasceu em Barros Filho, na periferia do Rio de Janeiro, uma comunidade entre o morro do Chapadão e o morro da Lagartixa. Quando tinha 4 anos, a pobreza levou sua família para o município de São João de Meriti, cidade onde Nascimento permanece morando, localizada na Baixada Fluminense. De acordo com a própria autora, na apresentação de seu livro Luiza e Babi e o Mistério do Lago de Onira, existe uma referência materna e paterna, pois herdou a escrita literária, primeiramente, da mãe, com as contações de histórias; e do pai, com as letras de samba canção.

A escritora possui mestrado em Semiologia e doutorado em Ciência da Literatura, ambos pela UFRJ. Atuou, por mais de trinta anos, na educação básica e, por quinze, no ensino superior. Realizou palestras no Pré-vestibular para Negros e Carentes, fundado na igreja da Matriz de São João de Meriti. Hoje, atua na área educacional, desenvolvendo projetos de leitura, letramento e escrita criativa com estudantes de escolas públicas. Elisabete Nascimento tem nove livros, dos quais oito são por autopublicação. São eles: Exu no Paço Imperial (2007); Diário de bordo do Almirante Negro (2011); Contos Pro(L)ibidos (2010); Os Sapatos de Té (2015); Ciranda de Meninos (2015); Luiza e Babi e o Mistério do Lago de Onira (2018); Máscara de flandres: em fragmentos (2018); Abayomi: Minha amiga imaginária (2019) e Amor de Abiku: Epifanias em um espelho estilhaçado de enigmas (2019).

Diante dos dados biográficos da autora, sabemos que Elisabete Nascimento é, além de escritora, professora e doutora, porém, por ser mulher negra e residir na Baixada Fluminense, ainda não obteve o reconhecimento e a visibilidade que deveria, mesmo tendo formação acadêmica dentro de uma instituição de ensino de referência. Por isso, consideramos que Diário de Bordo do Almirante Negro apresenta-se como um espaço para o protagonismo da escritora também. Podemos confiar nesta observação, pois, na dedicatória da obra, Nascimento demonstra sua angústia por saber que suas escritas ainda são silenciadas, porém, também é possível notar sua resistência, pois mesmo sendo invisibilizada, continua a escrever. 
Por vezes, falar ou escrever é sujeitar o Outro a mazelas, despeitos e indiferenças. Sob este prisma, este Outro é coisificado à condição de invisível, exótico ou inferior. Verbos que inventam e nos quais creem piamente. Em todo falar, reside um monstro devastador, contra o qual minha escritura está atenta a deslocar as ondas do oceano da imaginação. São deslocamentos, esforços, nem sempre lidos, nem sempre desejados, nem sempre garimpados. (NASCIMENTO, 2011, p. 5)

O trecho acima confirma a ideia de que o livro seria um meio para que as palavras da mulher negra possam ser lidas. Sabe-se da importância disso, pois possibilitar o lugar de fala e de escuta ao sujeito feminino é proporcionar para a mulher a chance de libertar-se da única condição que o contexto patriarcal e colonizador permite a ela: a de inferioridade.

Sabe-se que a denúncia levantada na dedicatória do livro não se trata apenas de uma experiência particular da autora e sim de algo sistemático de uma sociedade heteronormativa. A interdição da fala é comum dentro da realidade de mulheres negras. Por isso, cabe trazer para esta discussão o livro O que é lugar de fala?, de Djamila Ribeiro. Nele, a filósofa elenca o nome de mulheres negras que foram caladas ao longo da história através das estratégias de exclusão: o racismo, questões de classe e também preconceito linguístico.

Ribeiro ressalta a necessidade das mulheres negras resistirem à condição de passividade e tornarem-se protagonistas na produção de seus textos, assim, "colocando-as na situação de sujeitos e seres ativos que, historicamente, vêm pensando em resistências e re-existências" (RIBEIRO, 2017, p. 15).

Essa reflexão, leva-nos à crítica indiana Gayatri Spivak, principalmente, a sua obra Pode o subalterno falar?, que levanta questões importantes sobre o silêncio obrigatório para aqueles que foram colonizados. Spivak observa que, dentro do grupo de subalternizados, existem diferenças que colocam mulheres em condições mais inferiores do que a dos homens:

No contexto do itinerário obliterado do sujeito subalterno, o caminho da diferença sexual é duplamente obliterado. A questão não é a da participação feminina na insurgência ou das regras básicas da divisão sexual do trabalho, pois, em ambos casos, há "evidência". É mais uma questão de que, apesar de ambos serem objetos da historiografia colonialista e sujeitos da insurgência, a construção ideológica de gênero mantém a dominação masculina. Se, no contexto da produção colonial, o sujeito não tem história e não pode falar, o sujeito subalterno feminino está ainda mais profundamente na obscuridade. (SPIVAK, 2010, p. 66 - 67)

Como foi possível notar com o fragmento acima, em uma sociedade enraizada no colonialismo, 
sempre haverá desigualdade de gênero, estando a mulher negra na posição mais inferior. Nesse sentido, cabem algumas considerações sobre a autoria feminina. $\mathrm{O}$ artigo Infecção na sentença: $a$ escritora e a ansiedade de autoria das teóricas Gilbert e Gubar investiga como o processo de escrita entre homens e mulheres ocorre de forma divergente. Enquanto o escritor tenta se afastar dos textos predecessores, o que é nomeado de "ansiedade de influência", a mulher, a princípio, tem sua presença marcada, na literatura, como personagens estereotipadas. A escritora sofreria, assim, de "ansiedade de autoria". Diferente do homem que teme não ser original, a mulher sente medo "de não poder criar, porque ela nunca poderá vir a ser uma 'precursora', o ato de escrever irá isolá-la ou destruí-la" (GILBERT, GUBAR, 2017, p. 193). Assim, essa ansiedade é potencializada pelo temor de enfrentar os precursores homens, ocasionando na experimentação de sua própria identidade e na busca por um modelo feminino para se autenticar no espaço literário.

Nesse sentido, o protagonismo da autora contribui para a construção do protagonista da narrativa, que se apresenta na figura de um homem e, ao mesmo tempo, permite o protagonismo das personagens femininas. Seria essa mais uma diferença da escrita feminina que, diferente do que foi escrito por homens, não exclui, não estereotipa, tampouco silencia as vozes femininas dentro das obras.

\section{Os Protagonismos na Obra}

Como já dito anteriormente, Diário de Bordo do Almirante Negro permite o protagonismo de personagens masculinas e de personagens femininas. A narrativa começa com a aparição de três princesas, Yadetá, Yakalá e Yanassô, que vão ao encontro de João Cândido quando ainda era criança para entregar um pergaminho encantado, onde "enigmas devem ser decifrados" (NASCIMENTO, 2011 , p. 8). Interessa-nos ressaltar que o nome das princesas não foi escolhido por acaso, Nascimento buscou inspiração nas três mulheres africanas que fundaram o Candomblé da Barroquinha na Bahia no século XIX. ${ }^{3}$

Além de compor a narrativa com personagens importantes da nossa história, a escritora constrói a imagem das princesas com "marcas da herança: cabelos trançados, vestes de tradição" (NASCIMENTO, 2011, p. 8). A presença dessas personagens que "não são de faz de conta, nem de conto de fadas" (NASCIMENTO, 2011, p. 8) revela que há uma quebra de estereótipo na figura da princesa que aparece nos contos de fadas. Como nos lembra Chimamanda, "o problema com estereótipos não é que sejam mentira, mas que eles são incompletos. Eles fazem uma história se tornar a única história" (ADICHIE, 2019, p. 26). Ao ampliar o conceito de princesa e inserir personagens

3 Renato da Silveira, O candomblé da Barroquinha: processo de constituição do primeiro terreiro baiano de keto. Salvador: Maianga Edições, 2006. 
reais, o livro apresenta-se como um elemento importante para que crianças e adolescentes negros sintam-se representados tanto na ficção quanto na realidade. Observemos a ilustração a seguir.

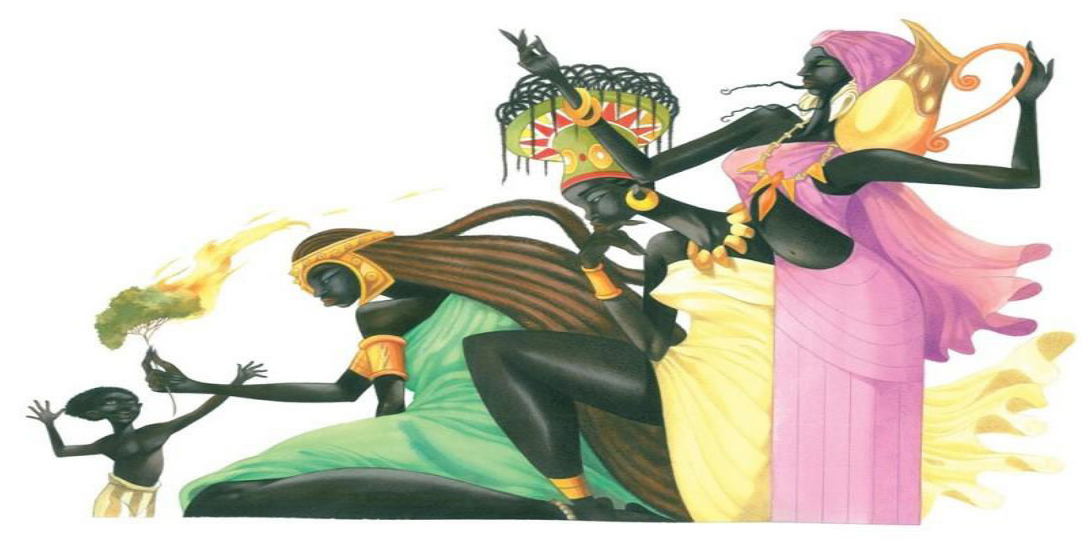

Figura 1 - As princesas Yadetá, Yakalá e Yanassô. Fonte: Fonte: ARAÚJO (2019) ${ }^{4}$

Interessa-nos notar que, para chegar ao corpo negro masculino interditado, foi necessária a presença do feminino. Além das princesas, a presença feminina também vai aparecer na imagem de Iansã $\tilde{5}^{5}$ ara caracterizar a força que o menino João iria precisar para enfrentar os desafios que

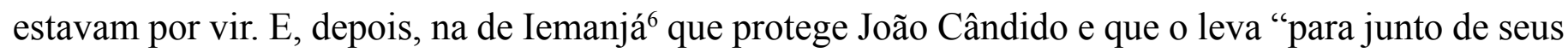
ancestrais" (NASCIMENTO, 2011, p. 44) ao final da narrativa. A partir dessas observações, o livro atua como uma ruptura na reprodução de produções literárias que elenca apenas o protagonismo masculino branco.

Sem dúvida, há uma preocupação por parte da escritora para com seu público leitor, neste caso, crianças e adolescentes. Durante a leitura, é notável o interesse em apresentar vocabulários africanos e explicar, através de um glossário que aparece na forma de um pergaminho, o significado de cada palavra. Tal estratégia indicaria uma intencionalidade autoral de sentido pedagógico emancipatório, comprometido com a formação de valores éticos e comportamentais.

Mesmo não sendo a proposta desta abordagem, cabe destacar a referência que a obra faz a religião de origem africana, tanto ao trazer a figura das três senhoras fundadoras do Candomblé, quanto pela presença dos orixás femininos. Sendo assim, Diário de bordo do Almirante Negro também possibilita enveredar a temática sobre intolerância religiosa, pois apresenta elementos da religião africana de maneira naturalizada, sem estereótipos que os demonizam.

O pergaminho entregue pelas princesas ao menino João Cândido conta, de forma resumida e poetizada, sua trajetória e a Revolta da Chibata. Importante relembrar que o pergaminho apresenta4 Fonte: ARAÚJO, Robson. Robson Araújo Ilustrações. Disponível em: http://robsonaraujoilustrador.blogspot.com/. Acesso em: 15 dez. 2019. 5 Orixá dos ventos e dos raios, que representa força.

6 Orixá das águas salgadas, considerada como aquela que protege os que entram no mar. 
se em forma de enigmas. Fato este que é interessante, pois é um aspecto que aguça a curiosidade do público leitor, que precisa decifrar esses "mistérios" no decorrer da história. Esta seria uma estratégia importante para que a criança também atue de forma ativa na narrativa, sendo ela também uma das protagonistas. Esse trecho é tão importante que, mesmo longo, merece ser reproduzido.

Serás poeta dos sete mares nos seios das águas da Guanabara. Imponente. Humano. Deveras humano. Firme. Altivo. Carinhoso. Justo-guerreiro. Aguerrido-amoroso. Divisor de águas oceânicas. Bordarás “amor”: curas. Aprenderás a língua eubá. Com ela, escreverás um diário. Aprenderás a ginga. Serás perseguido pelos dragões como um malta. Muito aprenderás com o Besouro, o cordão de ouro. Serás iniciado Yangi, o mensageiro dos deuses, senhor de muitas veredas. Descobrirás com o próprio sangue e suor que a Lei de Ouro não distribui o pão, milho, nem terra para o plantio. E então lutarás por seis dias. O Gigante vai parar ao ouvir teu nome, e, no sétimo dia, não descansarás. Não há descanso contra a escravidão. No Covil das Cobras, sobreviverás para decifrar enigmas dentro dos corações e tornar-se um griôt, contador da nossa história. Doze ministros de Aganju virão em teu auxílio. Antes, ele enviará um astro cortando o céu. Um cometa de Oiá, senhora dos ventos de mudanças. Prenúncio de luta contra a camarilha. O silêncio sobre ti será mais uma chibatada, mas, assim que a Terra girar cem vezes em torno do Sol, tuas ações e escrita dirão, enfim, que és um Almirante Negro. Nascerá Rosa; Benjamim, no picadeiro, alegrará teus dias; Heitor dará prazeres com aquarela; conhecerás o Lima e o Bispo. E muitos outros griôts e alabês. Juntos, construirão uma poética. O risco é não encontrar o tesouro! Quando, enfim, nos encontrarmos novamente, ele, o Bispo, te dará um presente que te trata de volta para os teus como um poeta de embate e não de embuste. (NASCIMENTO, 2011, p. 10)

As páginas seguintes, contam ao leitor de forma leve, a trajetória de João Cândido até ingressar na Marinha. Agora, veremos o protagonismo do personagem que representa um dos heróis da história brasileira que, finalmente, teve seu nome inscrito no Livro dos Heróis e das Heroínas do Estado do Rio de Janeiro em $2019^{7}$.

Importante é relembrar e destacar o nome e sobrenome do líder Revolta da Chibata. João Cândido Felisberto, nascido em 1880, em Encruzilhada do Sul, filho de escravizados, entrou para Marinha aos 13 anos de idade. Por muitos anos, navegou por todo o país e por outros continentes. Durante os 15 anos dedicados a Marinha de Guerra, foi, na maioria das vezes, instrutor, mas também

7 Lei ${ }^{\circ} 8.623$ de 18 de novembro de 2019. Disponível em: https://gov-rj.jusbrasil.com.br/legislacao/782167459/lei-8623-19-rio-de-janeiro-rj. Acesso em: 20 dez. 2019. 
exerceu as funções de maquinista, sinaleiro, artilheiro, entre outras, em distintos navios. Ao ter contato com marinhas de outros países, João Cândido e outros marujos não poderiam mais "admitir que, na Marinha do Brasil, um homem ainda tirasse a camisa para ser chibatado por outro homem" (NETO, 2003, p. 12 apud CÂNDIDO, 1968), como afirmou o Almirante em um depoimento para o ciclo de História Contemporânea do Museu da Imagem e do Som do Rio de Janeiro, em 29 de março de 1968.

A partir desta apresentação, é importante levantar algumas indagações a respeito de João Cândido: na escola, estuda-se sobre o momento histórico, no entanto, por que o nome de João Cândido não aparece como protagonista? Como esquecemos o protagonista de uma parte tão importante da nossa história? Na verdade, não há esquecimento, há silenciamento, há inúmeras tentativas de apagar o protagonismo de pessoas negras através de violências. Essa estratégia de dominação é mostrada nas páginas seguintes da obra, onde as imagens tornam-se mais pesadas, pois estamos diante dos momentos que antecedem o começo da Revolta da Chibata. A ilustração abaixo mostra o corpo de um homem negro amarrado a uma grande âncora. Podemos considerar, de acordo com o contexto, como a representação da Marinha e do racismo institucional.

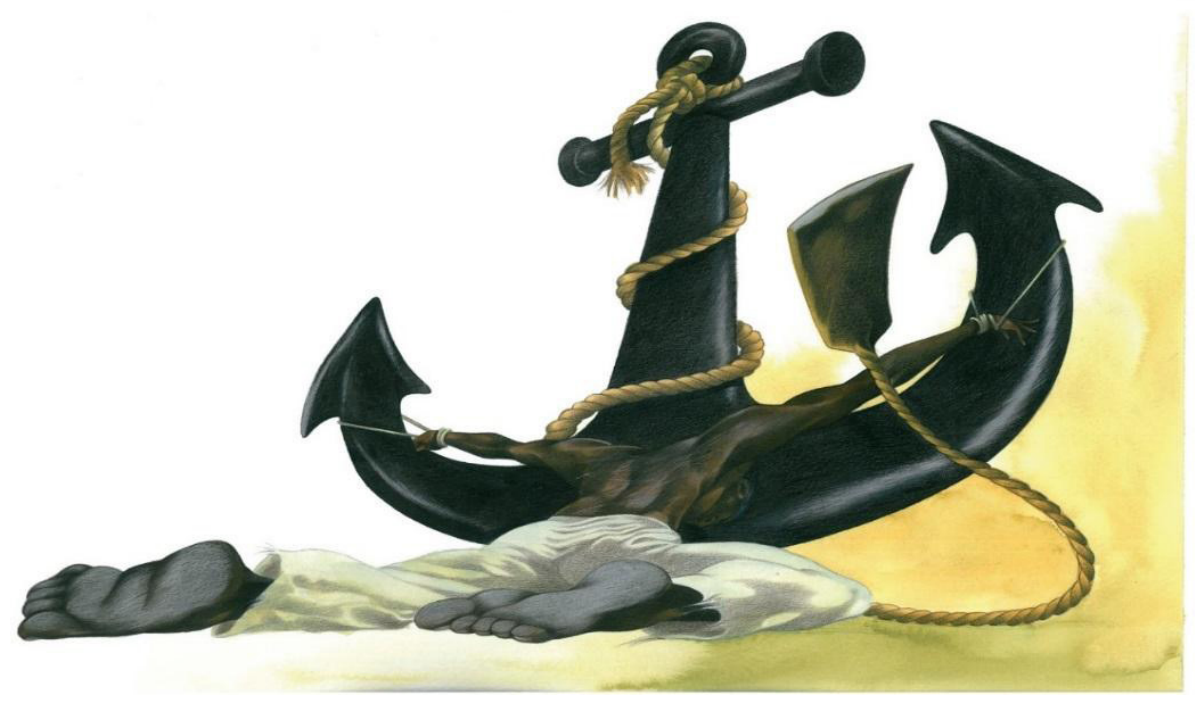

Figura 2 - Corpo de um marujo preso a uma grande âncora. FONTE: ARAUJO (2019) ${ }^{8}$

A história é contada por um narrador observador até certo momento. Depois nota-se que há uma democratização no ato de contar, pois Elisabete Nascimento ficcionaliza a voz de João Cândido, ou seja, o protagonista narra sua própria história, o que, na vida real, foi impedido de fazer por muito tempo, pois foi açoitado, preso na Ilha das Cobras e torturado. Mais uma vez, compreendemos a importância de reproduzir um fragmento um pouco extenso para que "escutemos" o herói "falar".

8 Fonte: ARAÚJO, Robson. Robson Araújo Ilustrações. Disponível em: http://robsonaraujoilustrador.blogspot.com/. Acesso em: 15 dez. 2019. 
Fui expulso da Marinha. Esta e a sociedade, uma coisa só. Correcional. Não consegui mudar um corpo de doutrinas militares. Mas parei o Gigante, a capital por seis dias. Eu parei a República que já nasceu velhaca. República de poucos. Da elite. Dos donos do poder. Do café com leite. Do feijão com arroz. A coisa pública nunca do povo foi. Nunca. O século XVI ainda vige. Não acabou. Sou estivador. Vendedor de peixe. Morador de São João de Meriti. Encontrei amigos quase no fim da vida. Estávamos no Palácio dos Loucos. Não sei bem se era sonho, ou imaginação, de quem me inspira. Mas encontrei o Lima Barreto, o poeta da prosa, e o tal Bispo, o poeta dos sonhos, de quem as três princesas falaram. Sofríamos de amor e solidão. Banzo. Conversávamos com os Ancestrais. Ouvíamos Deus o tempo inteiro. Bebíamos muito. Falar com o Supremo, com os Orixás, sobre o amor e sobre as princesas era coisa de maluco. Eu comecei a entender por que escapei da masmorra. Era muita proteção. A força vinha de nossa fé e precisão. Iemanjá, a mãe de todos os poetas e loucos, nunca nos abandonou. Recebeu no fundo do mar, ainda vivos, os marujos corajosos. Mas eu também deixei marcas no corpo de memória dos encouraçados: Minas Gerais, São Paulo... Eu queria a liberdade na Marinha; o Lima, a libertação na República e o Bispo do Rosário, a libertação do hospício. Era lobotomia, opressão e chibata. Opressão, chibata e lobotomia. E, afinal, loucos éramos nós?(NASCIMENTO, 2011, p. 35-36)

O excerto acima denuncia as opressões dos corpos de homens negros na sociedade. Como já foi dito, toda a obra é uma ficcionalização a partir da vida de João Cândido. O encontro do Almirante com Lima Barreto ${ }^{9}$ e Bispo do Rosário ${ }^{10}$, conforme ilustração abaixo, de fato, não ocorreu, trata-se também de uma ficcionalização feita por Elisabete Nascimento. Esses três homens passaram por experiências comuns, foram considerados loucos para que pudessem ser controlados. Isso significa que suas inteligências e consciências não eram interessantes para uma sociedade que detinha o poder sobre os corpos negros. A própria escritora afirma essa estratégia como manutenção de poder, em uma entrevista concedida ao programa Ciências e Letras do Canal Saúde em parceria com a Fio Cruz, que "há um investimento público de que isso seja percebido pelo negro como algo da cabeça dele, um delírio da cabeça dele sobre o racismo. E você percebe que é uma experiência coletiva de dor, de apagamento, de invisibilidade. E o risco é a perda de si"11.

9 Um dos principais escritores do pré-modernismo brasileiro. Suas obras denunciavam o racismo que perpassava a sociedade. Além de escritor, era jornalista.

10 Artista plástico brasileiro que desenvolvia sua arte a partir de objetos do cotidiano.

11 Entrevista sobre João Cândido concedida ao programa Ciências e Letras do Canal Saúde em parceria com a Fio Cruz. Disponível em: https:// www.youtube.com/watch?v=h2uVssgiDGA\&t=600s. Acesso em: 20 dez. 2019. 


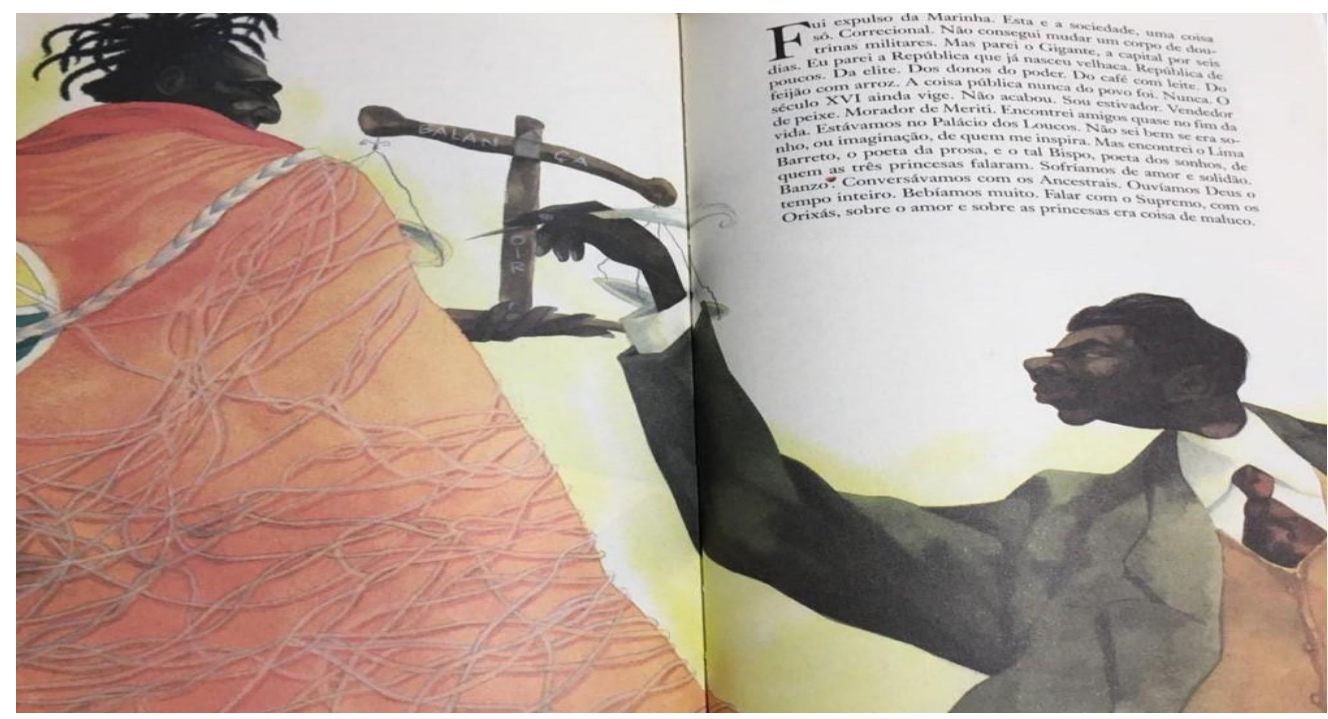

Figura 3 - Bispo do Rosário e Lima Barreto. FONTE: Fonte: NASCIMENTO (2011, p. 34 - 35)

A obra leva-nos a pensar no conceito de interseccionalidade. Ela se apresenta tanto em relação a raça, por denunciar as violências em relação ao corpo negro, quanto em relação a periferia, pois trata de um personagem importante para nossa história que morava na Baixada Fluminense, um dos lugares usado para confinar e/ou excluir determinados corpos. Além disso, João Cândido pertencia a uma classe social desfavorecida. Seguindo essa linha de pensamento, cabe a teoria de Kimberlé Crenshaw sobre a interseccionalidade pensada pelo movimento de mulheres negras e que Akotirene a descreve como uma ferramenta analítica que permite investigar o "cruzamento e sobreposição de gênero, raça e classe, modernos aparatos coloniais" (AKOTIRENE, 2018, p. 14).

A voz narrativa afirma que "esta história é sobre o corpo. O corpo de alta patente e o corpo de marujos. Corpos de desejos. Negros, em maioria" (NASCIMENTO, 2011, p. 28). Após ouvir a história de João Cândido, pode-se pensar no que Foucault chama de docilização do corpo, isto é, uma forma de adestramento, no qual o indivíduo é obrigado a seguir padrões. O poder sobre o corpo se apresenta através de punições e vigilância. A transformação de um corpo dócil não busca "unicamente o aumento de suas habilidades, nem tampouco aprofundar sua sujeição, mas a formação de uma relação que no mesmo mecanismo o torna tanto mais obediente quanto é mais útil, e inversamente" (FOUCALT, 1997, p. 135). Porém, mesmo diante de tanto investimentos para controlar, vimos que houve resistência de João Cândido.

O protagonismo deu-se a partir da resistência. Assim, consideramos a resistência como expressão do protagonismo como elemento fundamental que se apresenta também como fio condutor da história ficcional e das histórias reais que inspiraram o Diário de Bordo do Almirante Negro. A obra apresenta diversas resistências, como as que teoriza María Lugones e explica que "podemos pensar sobre as resistências íntimas e diárias" (LUGONES, 2019, p. 358) que referem-se ao "entrelaçado 
da vida social que acontece entre as pessoas que não estão assumindo papéis representativos" (LUGONES, 2019, p. 359). Seguindo este pensamento, a obra apresenta a resistência do corpo negro que "suporta", fisicamente, as chibatadas, mas contra elas se insubordina e constrói a resistência para manter a sanidade mental.

\section{Considerações Finais}

Após as reflexões aqui levantadas, notamos que a obra de Elisabete Nascimento rompeu com estereótipos que inferiorizam negros, as culturas e as religiosidades de matrizes africanas. Em o Diário de Bordo do Almirante Negro foi possível encontrar personagens que resgatam suas identidades a partir de suas resistências e de seus protagonismos. Logo, a narrativa contribui para (re) contar a história de João Cândido, na perspectiva do negro que outrora foi estigmatizado pelo racismo institucional.

Além disso, não podemos deixar de ressaltar que outra contribuição de extrema importância para o público infantojuvenil é a representatividade para as crianças negras. As imagens de João Cândido como um herói e das princesas fazem com que haja desconstrução do imaginário preconceituoso e, ao mesmo tempo, mostram o protagonismo de pessoas negras na história do país.

Portanto, foi possível verificar que a literatura infantojuvenil afro-brasileira torna-se um espelho para a formação da identidade das crianças e dos demais leitores por estimular a reflexão crítica ao mostrar problemas raciais e sociais, dar visibilidade ao protagonismo das personagens e promover o protagonismo do leitor, ao estimulá-lo a desvendar os enigmas que abrem a obra. E, além disso, o protagonismo da escritora que, certamente, resiste as discriminações de uma sociedade patriarcal e continua a escrever e a publicar mesmo que, ainda, não seja reconhecida. Nesse sentido, através dos protagonismos aqui apresentados, vimos que o subalternizado pode e fala, e, dessa maneira, ocupa os lugares de fala por meio da resistência.

\section{Referências Bibliográficas}

ADICHIE, Chimamanda Ngozi O perigo de uma história única. São Paulo: Companhia das Letras, 2019.

AKOTIRENE, Carla. Interseccionalidade. São Paulo: Pólen, 2019.

CANDIDO, Antonio. O direito à literatura. 4. ed. São Paulo: Duas Cidades, 2004.

FOUCAULT, Michel. Vigiar e Punir: história da violência nas prisões, 15. ed. Tradução Raquel Ramalhete. Petrópolis, 
RJ: Vozes, 1997.

GILBERT, Sandra; GUBAR, Susan. Infecção na sentença: a escritora e a ansiedade de autoria. In: Traduções da cultura - Perspectivas críticas feministas (1970-2010).Izabel Brandão, Ildney Cavalcanti, Claudia de Lima Costa, Ana Cecília Acioli Lima(Organizadoras). Florianópolis: EDUFAL; Editora da UFSC, 2017.

JOVINO, I. da S. Literatura Infanto-juvenil com personagens negros no Brasil. In: SOUZA, F; LIMA, M. N. (Org). Literatura Afro-brasileira. Salvador: Centro de estudos afroorientais; Brasília: Fundação Cultural Palmares, 2006.

LUGONES, María. Rumo a um feminismo decolonial. In: Pensamentos feministas: conceitos fundamentais. Org. Heloisa Buarque de Hollanda. Rio de Janeiro: Bazar do Tempo, 2019.

MARIOSA, G. S.; REIS, M. G. A influência da literatura infantil afro-brasileira na construção das identidades das crianças. Est. Literária, v. 8, p. 42-53, dez./2011.

MUNANGA, Kabengele. O negro no Brasil de hoje. Kabengele Munanga, Nilma Lino Gomes. São Paulo: Global, 2006.

NASCIMENTO, Elisabete. Diário de bordo do almirante negro. 1. ed. Rio de Janeiro: MR Bens, 2011.

. Luiza e Babi e o Mistério do Lago de Onira.1. ed. Rio de Janeiro: Mozerart Edições, 2018.

NETO, José Miguel Arias. João Cândido 1910-1968: arqueologia de um depoimento sobre a Revolta dos Marinheiros. História Oral da ABHO, Rio de Janeiro, jun. 2003, p. 159-85. Disponível em: https://revista.historiaoral.org.br/index. php?journal=rho\&page=article\&op=view\&path $\% 5 \mathrm{~B} \% 5 \mathrm{D}=70 \&$ path $\% 5 \mathrm{~B} \% 5 \mathrm{D}=62$. Acesso em: 15 dez. 2019.

SILVEIRA, Renato da. O candomblé da Barroquinha: processo de constituição do primeiro terreiro baiano de keto. Salvador: Maianga Edições, 2006.

SPIVAK, Gayatri C. Pode o subalterno falar?. Belo Horizonte: UFMG, 2010.

RIBEIRO, Djamila. O que é lugar de fala?. Belo Horizonte: Letramento: Justificando, 2017.

Entrevista sobre João Cândido concedida ao programa Ciências e Letras do Canal Saúde em parceria com a Fio Cruz. Disponível em: https://www.youtube.com/watch?v=h2uVssgiDGA\&t=600s. Acesso em: 20 dez. 2019. 